\title{
SYMPATHETIC OVERACTIVITY AND CORONARY RISK IN HYPERTENSION.
}

John Amerena and Stevo Julius, University of Michigan, 3918 Taubman center 481090356, Ann Arbor, MI, USA.

The association between sympathetic overactivity and hypertension has been extensively studied but the link between sympathetic excess and coronary risk has not been clearly defined. There is a mounting body of evidence that suggests that there is a strong association between the sympathetic nervous system and increased cardiac risk independent of hypertension which has been gleaned from observational data gathered in epidemiological studies and supported by clinical studies undertaken in hypertensive patients.

The Tecumseh study is a large scale observational and epidemiological study looking at the associations and predictors of hypertension in a rural community in Tecumseh, Michigan. Nearly one thousand subjects were enrolled into the study and anthropometric, hemodynamic and metabolic data were collected at several time points. When first examined as children those subjects who were ultimately to develop borderline hypertension had significantly faster heart rates than their future normotensive counterparts despite having comparable blood pressures as children.(1) As they aged the difference between the pulse rate was maintained and the blood pressure in the borderline hypertensive group had become elevated. When examined as adults (18-42 years) the differences in pulse rate and blood pressure persisted between the groups and elevated plasma noradrenaline was demonstrated in the hyperkinetic (high cardiac output, increased heart rate) hypertensive subjects. An significant increase in cardiac risk factors was found in the hypertensive group as a whole and also in the subpopulation of "pure" hyperkinetic hypertensive subjects (2) and a strong correlation between diastolic blood pressure and these risk factors was also found (3). This data suggests that there was a relative overactivity of the sympathetic nervous system present from an early age in the subjects who were to develop borderline hypertension and that this persisted into at least early adulthood. It also raises the intriguing possibility that sympathetic excess could not only be responsible for the blood pressure elevation in these subjects but also independently result in the increase in coronary risk factors. A hypothetical schema for just such an association will be described where excess sympathetic tone is the underlying pathophysiological state that leads to an increased tendency to atherosclerosis and insulin resistance as well as a propensity to coronary thrombosis, coronary spasm and arrhythmia's.

Insulin resistance has been shown to be associated with hypertension (4) and is accompanied by an increased coronary morbidity (5). Excess sympathetic tone may produce insulin resistance by promoting $\alpha$-adrenergic vasoconstriction and reducing the delivery of insulin and glucose to skeletal muscle, which is thought to be the site of insulin resistance in hypertension. Jamerson 's work (6) lends support to this concept when it was demonstrated that decreased blood flow in the human forearm produced by reflex activation of the sympathetic nervous system results in decreased glucose utilization, a condition analogous to insulin resistance. This type of sympathetically mediated insulin resistance may be compounded by the trophic effects of elevated insulin on the vascular wall (7) and by vascular rarefaction which has been documented to occur in hypertension (8). Further evidence for a role of the sympathetic nervous system in altered insulin sensitivity in 
hypertension comes from Diebert and De Fronzo's (9) work showing that an acute decrease in insulin sensitivity can be produced by adrenaline infusion and from studies describing that chronic $\beta$-adrenergic stimulation leads to an increase in insulin resistant fast twitch muscle fibers in rats (10).

Early studies by Julius et al.(11) found that intravenous infusion of propranolol caused an acute decrease in plasma volume (with an increase in hematocrit), presumably due to the effect of unopposed $\alpha$-adrenergic tone on the post-capillary venules. Cohn et al. (12) found that this was not a general response to vasoconstriction when they looked at changes in plasma volume induced by infusion of AII and norepinephrine. At similar levels of increase in blood pressure and forearm resistance norepinephrine but not angiotensin infusion produced a significant decrease in plasma volume. When hematocrit was examined in relation to blood pressure in the Tecumseh study it was found that the subjects with the highest hematocrit were the subjects in the hypertensive blood pressure group (13). These subjects had significantly increased coronary risk factors and elevated indices of sympathetic tone relative to their normotensive counterparts. This observational data, taken in the context of the previous studies lends support to the concept of increased sympathetic tone producing an elevated hematocrit and thus an increased risk of coronary thrombosis. This risk of thrombosis may be even more increased by increased platelet aggregability, as elevated $\beta$-thromoglobulin has been described in association with markers of increased sympathetic tone in hypertension (14).

Autonomic blockade in borderline hypertensive volunteers has consistently demonstrated increased sympathetic tone in conjunction with a reciprocal decrease in parasympathetic tone (15). This decrease in parasympathetic tone tends to persist even as markers of sympathetic excess diminish during the course of hypertension becoming established. Excess sympathetic tone may predispose to the development of left ventricular hypertrophy by increasing blood pressure but can amplify this tendency by exerting trophic effects on myocytes directly (16) and by promoting renin release and increased levels of angiotensin II which can also act as a pressure independent trophic factor (17). Left ventricular hypertrophy is commonly seen in hypertension (18) and is associated an increased cardiovascular risk, predominantly due to sudden death, presumably arrythmic in origin. Excess ventricular ectopic activity has been demonstrated in hypertensive patients with and without LVH and this predisposition may be increased by the autonomic imbalance seen in hypertension, perhaps by decreasing the arrythmic threshold.

Chronic elevation of the blood pressure leads to structural changes in the vascular wall characterized by an increase in the wall-lumen ration. These pressure induced changes may be accentuated by the trophic effects of increased sympathetic tone and render the vessel hyper-reactive to any vasoconstricting influence. Egan et al. (19) demonstrated this when they showed that forearm vascular resistance increased to a greater extent in hypertensive patients in response to norepinephrine infusion than in normotensive controls, and that the response was even greater in those who had elevated plasma norepinephrine levels. Such changes may take place in the take place in the coronary microcirculation, even in the absence of LVH (20), and thus make the hypertensive patient particularly prone to coronary artery spasm.

Sympathetic overactivity is associated with pressure dependent and pressure independent effects on the cardiovascular system. The link between excess sympathetic tone and coronary risk is conceptually appealing and is supported by the evidence 
accumulated to date, but is worthy of further study to more clearly define the association and the magnitude of risk.

\section{References:}

1. Julius S, Jamerson K: Sympathetics, insulin resistance and coronary risk in hypertension: the 'chicken-and-egg' question. J Hypertens 1994;12:495-502..

2. Amerena J and Julius S. The rRole of the Autonomic Nervous System in Hypertension. Hypertens Res1995 18: 2 99-110.

3. Julius S, Jamerson K, Mejia A, Krause L, Schork N, Jones K. The association of borderline hypertension with target organ changes and higher coronary risk. The Tecumseh Blood Pressure Study. J AMA 1990264 (3) 354-358

4. Ferrannini E, Buzzigoli G, Bonadonna R, Giorico MA, Oleggini M, Graziadei L, Pedrinelli R, Brandi L, Bevilacqua S: Insulin resistance in essential hypertension. N Engl J Med 1987;317:350-357.

5. Pyorala K, Savolainen E, Kaukola S, Haapakoski J: Plasma insulin as a coronary heart disease risk factor: relationship to other risk factors and predictive value during $91 / 2$ year follow-up of the Helsinki Policemen Study population. Acta Med Scand Suppl 1985;701:38-52.

6. Jamerson KA, Julius S, Gudbrandsson T, Andersson O, Brant DO: Reflex sympathetic activation induces acute insulin resistance in the human forearm. Hypertension 1993;21(5):618-623.

7. Stout RW, Bierman EL, Ross R: Effect of insulin on the proliferation of cultured primate arterial smooth muscle cells. Circ Res 1975;36:319-327.

8. Greene AS, Tonellato PJ, Lui J, Lombard JH, Cowley AW,Jr.: Microvascular rarefaction and tissue vascular resistance in hypertension. Am J Physiol 1989;256:H126H131.

9. Deibert DC, DeFronzo RA: Epinephrine-induced insulin resistance in man. J Clin Invest 1980;65:717-721.

10. Zeman RJ, Ludemann R, Easton TG, Etlinger JD: Slow to fast alterations in skeletal muscle fibers caused by clenbuterol, a beta-2-receptor agonist. Am J Physiol 1988;254:E726-E732.

11. Julius S, Pascual AV, Abbrecht P, London R: Effect of beta-adrenergic blockade on plasma volume in human subjects. Proc Soc Exp Biol Med 1972;140:982-985.

12. Cohn JN: Relationship of plasma volume changes to resistance and capacitance vessel effects of sympathomimetic amines and angiotensin in man. Clin Sci 1966;30:267-278.

13. Smith S, Julius S, Jamerson K, Amerena J and Schork N. Hematacrit levels and physiologic factors in Tecumseh, Michigan. J Hypertens 1994;12:4 455-461.

14. Kjeldsen SE, Gjesdal K, Eide I, Aakesson I, Amundsen R, Foss OP, Leren P: Increased beta-thromboglobulin in essential hypertension: Interactions between arterial plasma adrenaline, platelet function and blood lipids. Acta Med Scand 1983;213:369-373.

15. Julius S, Pascual AV, London R: Role of parasympathetic inhibition in the hyperkinetic type of borderline hypertension. Circulation 1971;44:413-418.

16. Simpson P: Norepinephrine-stimulated hypertrophy of cultured rat myocardial cells is an alpha-1 adrenergic response. J Clin Invest 1983;72:732-738.

17. Schelling P, Fischer H, Gantlen D: Angiotensin and cell growth: a link to cardiac hypertrophy? J Hypertens 1991;9:3-15. 
18. Kannel WB, Gordon T, Castelli WP, Margolis JR: Electrocardiographic left ventricular hypertrophy and risk of coronary heart disease. The Framingham study. Ann Intern Med 1970;72:813-822.

19. Egan B, Panis R, Hinderliter A, Schork N, Julius S: Mechanism of increased alphaadrenergic vasoconstriction in human essential hypertension. J Clin Invest 1987;80:812817.

20. Brush JE, Cannon RO, Schenke WH, Bonow R, Leon M, Maron B, Epstein S: Angina due to coronary microvascular disease in hypertensive patients without left ventricular hypertrophy. N Engl J Med 1988;319 (20):1302-1307. 